\title{
Relationship of the Manifestations of Tuberculosis to CD4 Cell Counts in Patients with HIV Infection
}

\author{
Nazish Fatima ${ }^{1}$, Abida Malik ${ }^{1}$, Parvez Anwar Khan ${ }^{1}$, Sana Ali $^{1}$ and Mohd. Shameem ${ }^{2}$ \\ 1. Department of Microbiology J.N.M.C.H, Aligarh Muslim University, Aligarh, India \\ 2. Department of Tuberculosis and Respiratory diseases J.N.M.C.H, Aligarh Muslim University, Aligarh, India
}

\begin{abstract}
Objectives: To study the various clinical and radiological manifestations of tuberculosis, AFB status, tuberculin reactivity in HIV positive patients and its relationship with the CD4 cell counts. Methods: Symptomatic patients with confirmed serodiagnosis of HIV infection were screened for pulmonary tuberculosis (PTB) as well as for extra-pulmonary tuberculosis (EPTB), diagnosis of tuberculosis was made using different modalities.Tuberculin testing and CD4 cell counts were also determined. Results: Seven hundred and seventy two patients with HIV infection were included in the study. Eighty seven patients (11.3\%) were diagnosed with concurrent active tuberculosis. Pulmonary tuberculosis only was seen in 28 of the $87(32.2 \%)$ patients. Forty two patients (48.3\%) had only extra-pulmonary tuberculosis, whereas $17(19.5 \%)$ had both pulmonary as well as extra pulmonary tuberculosis. Commonest form of EPTB in our study was tubercular lymphadenopathy, detected in $19(21.8 \%)$ patients. On tuberculin testing, out of total 87 patients, 33 (37.9\%) had induration $\geq 5 \mathrm{~mm}$ (sensitivity 37.93\%) while $23(26.4 \%$ ) developed induration $\geq 10 \mathrm{~mm}$ (sensitivity $26.43 \%)$. Chest X-ray of $42(48.3 \%)$ of HIV-TB patients showed tubercular findings. In patients with CD4 count $<200$ cells $/ \mu$, fourteen patients $(66.7 \%)$ had atypical findings while 7 (33.4\%) patients had typical radiographic picture. AFB smear-negativity and culture-positivity in PTB was more common with decrease in CD4cell count. Conclusions: The lack of rapid and accurate TB diagnostic tools and the lack of a standardized symptom and sign-based screening strategy has posed a challenge to the accurate and prompt diagnosis of tuberculosis in HIV infected patients. Available information, experience, and data have to be used to develop a simple and standardized TB screening strategy for use in settings with a high prevalence of HIV infection.
\end{abstract}

Key words: HIV, tuberculosis, co-infection, CD4.

\section{Introduction}

Advent of HIV/AIDS pandemic has led to dramatic resurgence of tuberculosis worldwide, resulting in increased morbidity and mortality. HIV and Mycobacterium tuberculosis have a synergistic interaction; each propagates progression of the other. Globally, nearly 2 billion people are infected with Mycobacterium tuberculosis and at the end of 2010; an estimated 34 million people (31.6 million-35.2 million) were living with HIV worldwide [1]. India has an adult HIV prevalence of 0.31 percent $(0.25 \%-0.39 \%)$ and an estimated 23.9 lakh people are living with HIV/AIDS [2]. Twenty five to sixty five

Corresponding author: Nazish Fatima, assistant professor, research fields: Immunology, Tuberculosis, Mycology E-mail: medicalmicrobiologyjnme@gmail.com. percent of people infected with HIV have been observed to have active TB of one organ or the other in different reports from India [3, 4].

It is known that $\mathrm{TB}$ is the commonest opportunistic infection among HIV-infected individuals and the most common cause of death in patients with AIDS [5]. In India on the other hand, it is noted that about five percent tuberculosis patients registered under RNTCP also have HIV infection [6]. As HIV related immunosuppression increases, the clinical and radiographic picture of tuberculosis also change. While TB can develop at any CD4 count, extrapulmonary and disseminated form of the disease are more common as immunodeficiency increases [7-9]. Co-infection with HIV infection leads to difficulties in both the diagnosis and treatment of tuberculosis, increase risk of death, treatment failure 
and relapse. We conducted this study to find out different clinical and radiological manifestations of tuberculosis, AFB status, tuberculin reactivity in HIV positive patients and its relationship with the CD4 cell counts.

\section{Patients and Methods}

The study group comprised of 772 symptomatic patients with confirmed serodiagnosis of HIV infection attending the ICTC /ART centre or admitted patients at $\mathrm{JN}$ medical college and Hospital, Aligarh over a period of 3 years (November 2008 to 2011).

All patients were screened for pulmonary tuberculosis (PTB) as well as for extra-pulmonary tuberculosis (EPTB), with a detailed clinically history, physical examination, $x$-raychest, sputum for acid fast bacilli (AFB). Fine needle aspiration cytology (FNAC) and lymph-node biopsy, lumbar puncture, ultrasonography of abdomen, endometrial biopsy and pleural aspiration were done wherever required. In addition, patients already diagnosed with active tuberculosis and presented to the centre for antiretroviral therapy for a concurrent HIV infection, were also included in this study.

The diagnosis of tuberculosis was made on the basis of symptoms and signs compatible with tuberculosis and/or radiological evidence of active tuberculosis; demonstration of acid fast bacilli (AFB) from a clinical specimen (sputum, FNAC of lymph node, pleural fluid, endometrial tissue, cerebrospinal fluid), mycobacterial culture, histopathological demonstration of typical caseous granulomatous reaction and pleural/ascitic fluid analysis showing evidence of lymphocytic exudative effusion and CSF showing lymphocytic pleocytosis and low CSF glucose.Tuberculin test was also performed in each patient with 5TU PPD-S. An induration of $5 \mathrm{~mm}$ or more after 48-72 hours was considered positive [5]. HIV infection was diagnosed using three antigenically different rapid kits as per the national HIV testing policy [10]. CD4 cell counts were determined by flow-cytometry technique by PartecCy-Flow Counter (Germany).

\section{Results}

Seven hundred and seventy two patients with HIV infection were included in the study. Eighty seven patients (11.3\%) were diagnosed with concurrent active tuberculosis (HIV-TB). Of these patients, 66 $(75.8 \%)$ were male and $21(24.2 \%)$ were females. The mean age of the HIV-TB patients was 33.6 years (Table 1). Heterosexual contact was the predominant (96.4\%) route of transmission of HIV infection in this study.

Fever was seen in 81 (93.1\%) out of 87 HIV-TB patients and the mean duration of fever was 2 months (Table 2). Forty eight (55.2\%) patients presented with weight loss of more than $10 \%$.

Regarding tuberculosis, pulmonary tuberculosis only was seen in 28 of the $87(32.2 \%)$ patients. Forty two patients (48.3\%) had only extra-pulmonary tuberculosis, whereas 17 (19.5\%) had both pulmonary as well as extra pulmonary tuberculosis (Table 3, Fig. 1). Commonest form of EPTB in our study was tubercular lymphadenopathy, detected in 19 (21.8\%) patients followed by tuberculosis of CNS in 13 $(14.9 \%)$ patients. Abdominal tuberculosis in 11 (12.7\%), Genital tuberculosis in 8 (9.2\%). Tubercular pleural and pericardial effusion were reported in 7 $(8 \%)$ and $1(1.1 \%)$ patients, respectively. The mean CD4 count of patients with only pulmonary TB was 132.3 cells/ $\mu$ l (range 44-321) while those with only extra pulmonary TB had CD4 cell count mean 107.1

Table 1 Age distribution of the patients.

\begin{tabular}{|c|c|c|}
\hline \multirow{2}{*}{ Age group(range in years) } & \multicolumn{2}{|c|}{ No. of patients $(\mathrm{n}=87)$} \\
\cline { 2 - 3 } & Males & Females \\
\hline $0-10$ & 3 & 1 \\
\hline $11-20$ & 6 & 2 \\
\hline $21-30$ & 20 & 13 \\
\hline $31-40$ & 26 & 3 \\
\hline $41-50$ & 10 & 2 \\
\hline$>50$ & 1 & 0 \\
\hline Total & 66 & 21 \\
\hline
\end{tabular}


Table 2 Common symptoms in HIV-TB Co-infected patients $(\mathbf{n}=\mathbf{8 7})$.

\begin{tabular}{|l|c|c|c|}
\hline Symptoms & $\begin{array}{l}\text { No. of } \\
\text { patients }\end{array}$ & $\begin{array}{l}\text { Percentage } \\
(\%)\end{array}$ & $\begin{array}{l}\text { Mean } \\
\text { duration } \\
\text { (weeks) }\end{array}$ \\
\hline Fever & 81 & 93.1 & 8 \\
\hline Loss of appetite & 70 & 80.4 & 6 \\
\hline Cough & 56 & 64.4 & 4 \\
\hline Weight loss & 48 & 55.2 & 12 \\
\hline Diarrhea & 32 & 36.8 & 3 \\
\hline Chest pain & 28 & 32.2 & 3 \\
\hline Pain abdomen & 25 & 28.7 & 4 \\
\hline $\begin{array}{l}\text { Menstrual } \\
\text { irregularities }\end{array}$ & 22 & 25.3 & 12 \\
\hline $\begin{array}{l}\text { Neurological } \\
\text { manifestations }\end{array}$ & 16 & 18.4 & 1 \\
\hline
\end{tabular}

Table 3 Distribution of pulmonary and extrapulmonary tuberculosis.

\begin{tabular}{|c|c|c|c|c|}
\hline & & \multicolumn{2}{|c|}{$\begin{array}{l}\text { Number of } \\
\text { patients }\end{array}$} & \multirow[t]{2}{*}{$\begin{array}{l}\text { Total } \\
(\%)\end{array}$} \\
\hline & $\mathrm{CD} 4 / \mathrm{mm}^{3}$ & $<200$ & $>200$ & \\
\hline $\begin{array}{l}\text { Pulmonary } \mathrm{TB} \\
\text { only }\end{array}$ & & 11 & 17 & $\begin{array}{l}28 \\
(32.2)\end{array}$ \\
\hline \multirow{6}{*}{$\begin{array}{l}\text { Extrapulmonary } \\
\text { TB (with or } \\
\text { without PTB) }\end{array}$} & TB of & 7 & 12 & 19 \\
\hline & CNS TB & 9 & 4 & $13(14.9)$ \\
\hline & $\begin{array}{c}\text { Abdominal } \\
\text { TB }\end{array}$ & 6 & 5 & $\begin{array}{l}11 \\
(12.7)\end{array}$ \\
\hline & Genital TB & 3 & 5 & $8 \quad(9.2)$ \\
\hline & $\begin{array}{c}\text { Tubercular } \\
\text { pl.eff. }\end{array}$ & 3 & 4 & $7 \quad(8.0)$ \\
\hline & $\begin{array}{l}\text { Pericardial } \\
\text { effusion }\end{array}$ & 1 & - & $1 \quad(1.1)$ \\
\hline
\end{tabular}

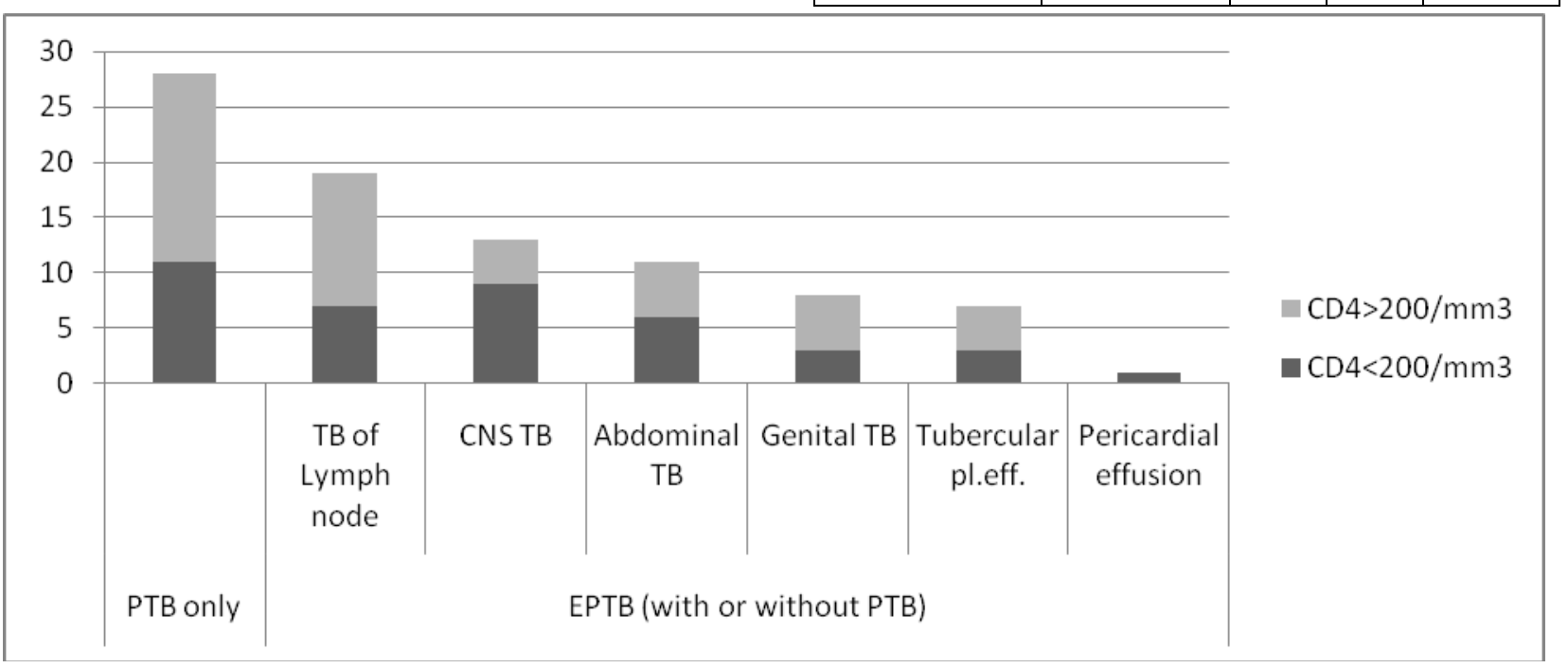

Fig. 1 Distribution of pulmonary and extrapulmonary tuberculosis.

cells/ $\mu$ l (range 38-285). The mean CD4 was observed to be lower in the patients with both PTB and EPTB (mean 91.5, range 28-249).

On tuberculin testing, out of total 87 patients 33 (37.9\%) had induration $\geq 5 \mathrm{~mm}$ (sensitivity $37.93 \%$ ) while $23(26.4 \%)$ developed induration $\geq 10 \mathrm{~mm}$ (sensitivity 26.43\%).The sensitivity for detecting active TB, stratified by both $5 \mathrm{~mm}$ and $10 \mathrm{~mm}$ cut-offs and by CD4 count strata (Table 4) was maximum when considering induration of $5 \mathrm{~mm}$ in patients with CD4 cell count below 200 cells $/ \mu 1$.

Chest X-ray (CXR) of 42 (48.3\%) of HIV-TB patients showed tubercular findings. In patients with CD4 count $<200$ cells $/ \mu$ l, fourteen patients $(66.7 \%)$ had atypical findings (Fig. 3) in the form of intrathoracic adenopathy, focal lower or middle lobe infiltrates, and diffuse miliary or nodular infiltrate, 3 patients had a normal CXR and were considered atypical, while $7(33.4 \%)$ patients had typical radiographic picture (Fig. 2). In patients with $\mathrm{CD} 4$ count $>200$ cells $/ \mu 1$, atypical findings were seen in 6 $(25 \%)$ while typical radiographic picture was seen in $18(75 \%)$ patients (Table 5).

Of the 87 patients of HIV-TB, sputum was found to be positive for AFB in 17 patients out 45 patients who had pulmonary involvement.Fine needle aspirate of lymph nodes revealed AFB in 9 and in 4 specimens of endometrial tissue. The mean CD4 count in sputum 
smear positive cases was 129.8 cells/ $\mu$ l (range $35-311)$ compared to the mean CD4 count of 107.4 cells/ $\mu 1$ (range 28-275) in smear negative cases.

AFB smear-negativity, culture-positivity in PTB was more common with decrease in CD4cell count. Of 21 subjects with a CD $<200$ cells/ $\mu$ and PTB, 12
(26.8\%) were AFB smear-negative as compared to10 of $24(22.2 \%)$ with a CD4 $>200$ cells $/ \mu 1$. As patients presented with lower CD4 counts, there was a significant decrease inhigh bacillary burden $(3+$ AFB) smears and an increase in lowbacillary burden (1+ AFB) smears.

Table 4 Tuberculin skin tests by CD4 count strata for patients with tuberculosis.

\begin{tabular}{|c|c|c|c|c|c|}
\hline & $\begin{array}{c}\text { Patients per } \\
\text { strata }\end{array}$ & $\begin{array}{c}\text { Patients with induration } \\
\geq 5 \mathrm{~mm}(\%)\end{array}$ & senstivity & $\begin{array}{c}\text { Patients with induration } \\
\geq 10 \mathrm{~mm}(\%)\end{array}$ & senstivity \\
\hline Overall cohort & 87 & $33(37.9)$ & 37.93 & $23(26.4)$ & 26.43 \\
\hline $\begin{array}{c}\text { CD4 } \\
\left(\text { cells } / \mathrm{mm}^{3)}\right.\end{array}$ & & & & & \\
\hline$<200$ & 35 & 9 & 25.71 & 5 & 14.28 \\
\hline$>200$ & 52 & 24 & 46.15 & 18 & 34.61 \\
\hline
\end{tabular}

Table 5 Radiographic appearance by CD4 T Lymphocyte Count.

\begin{tabular}{|c|c|c|}
\hline CD4 Count (Cells/mm $\mathbf{m m}^{3)}$ & Radiographic Appearance & No. of Subjects* \\
\hline \multirow{12}{*}{$\begin{array}{c}<200 \\
(n=21)\end{array}$} & \multicolumn{2}{|c|}{ Atypical presentation $(n=14)$} \\
\hline & Unifocal alveolar opacity & 5 \\
\hline & Multifocal alveolar opacity & 3 \\
\hline & Unifocal interstitial opacity & 2 \\
\hline & Cavitary opacity & 2 \\
\hline & Mediastinal or hilaradenopathy & 3 \\
\hline & Miliary nodules & 2 \\
\hline & Pleural effusion & 3 \\
\hline & Normal CXR & 3 \\
\hline & \multicolumn{2}{|c|}{ Typical presentation $(n=7)$} \\
\hline & Unilateral apical opacity & 5 \\
\hline & Biapical opacities & 2 \\
\hline \multirow{8}{*}{$\begin{array}{c}>200 \\
(n=24)\end{array}$} & \multicolumn{2}{|c|}{ Atypical presentation $(n=6)$} \\
\hline & Unifocal alveolar opacity & 4 \\
\hline & Mediastinaladenopathy & 2 \\
\hline & Pleural effusion & 1 \\
\hline & & \\
\hline & Typical prese & \\
\hline & Unilateral apical opacity & 12 \\
\hline & Biapical opacities & 6 \\
\hline
\end{tabular}

*Totals for various radiographic findings sum to greater than the total of 45 subjects with PTB because some subjects had more than one radiographic finding. 


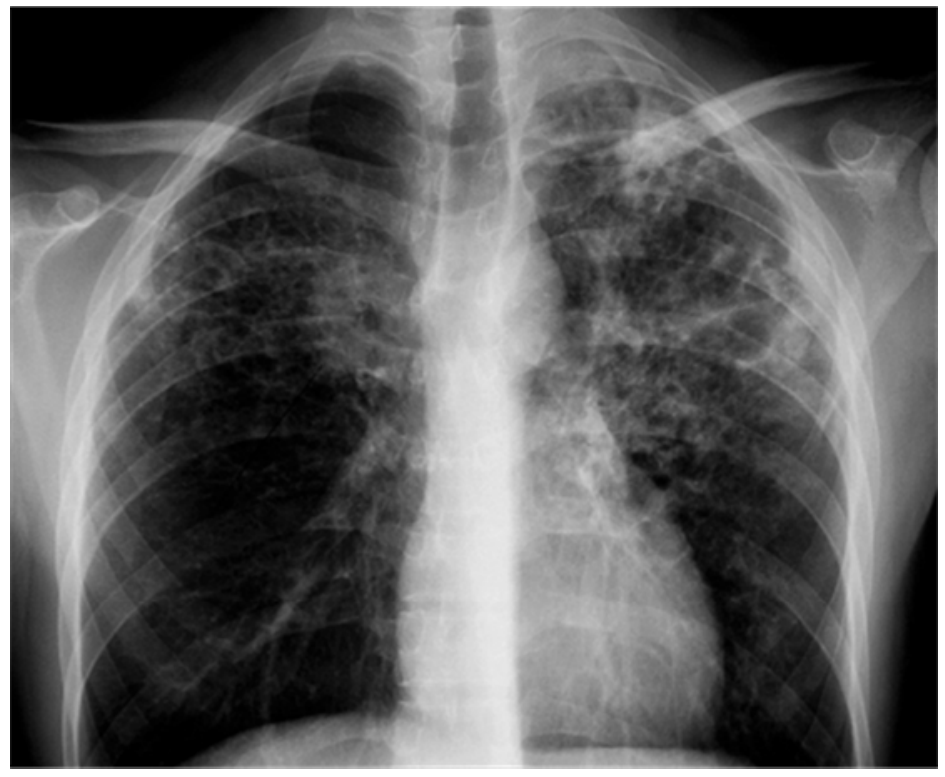

Fig. 2 Typical postprimary TB radiographic pattern showing a left upper lobe cavitary infiltrate.

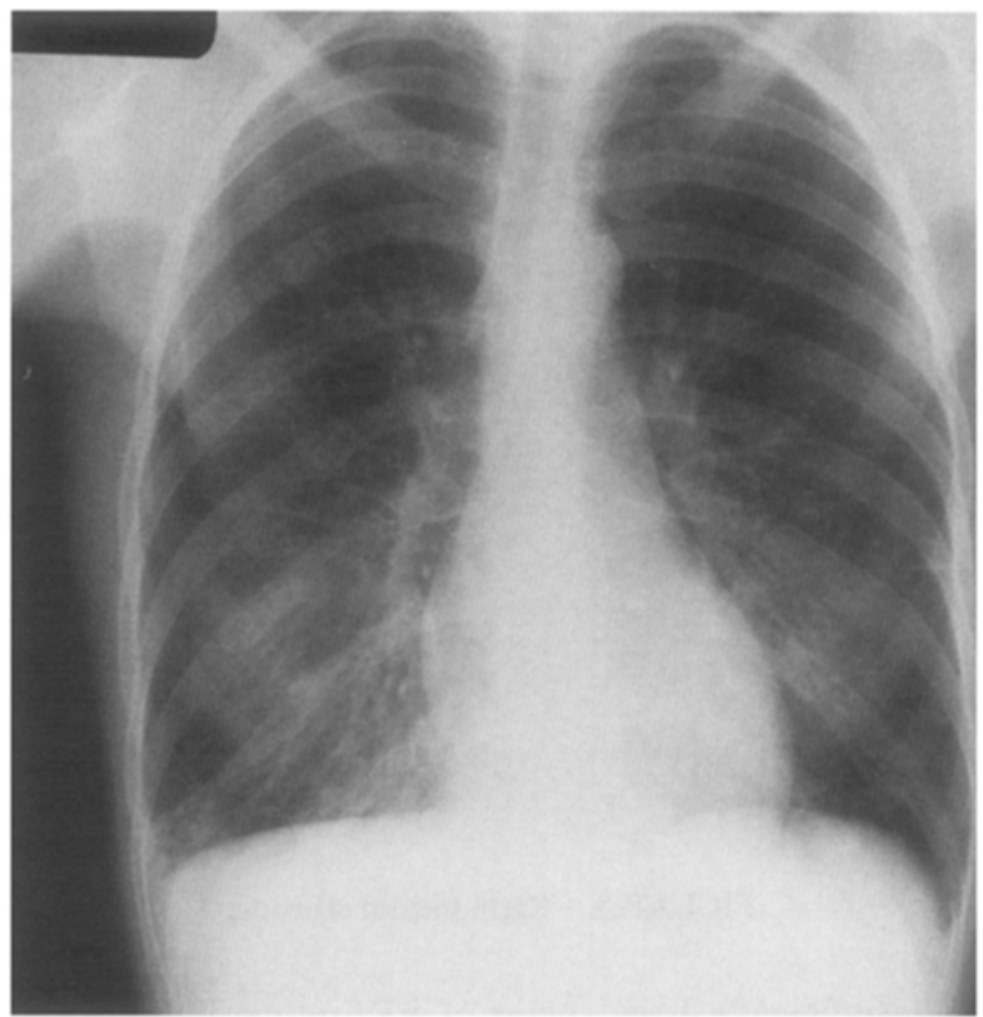

Fig. 3 Atypical radiographic pattern showing right lower lobe infiltrate.

\section{Discussion}

Tuberculosis seen in HIV infected individuals is the most common opportunistic infection. It is also hypothesized that persons infected with tubercle bacillus are at higher risk of developing clinical disease if they become infected with HIV [7]. Their clinical, radiological, and bacteriological manifestations vary with the level of immunosuppression and CD4 lymphocyte counts [8, 9]. 
In the present study $66(75.8 \%)$ patients were male and $21(24.2 \%)$ were females.The striking male predominance noted in the present study has also been reported by other authors $[11,12]$ The mean age of the HIV-TB patients was 33.6 years. Most of our study group patients $(56.2 \%)$ were in the age group of 26-35 years, which is the sexually active age and is also the most productive in one's life.

The occupational profile of our patients revealed that majority of them were farmers and laborers followed by transport drivers. Mohanty et al. [13] reported $36.8 \%$ patients working as manual laborers while Rajsekaran et al. [14] found majority (55.6) of patients working as farmers. Other authors [12] have found sero-positivity rate was highest among those who were unemployed $(40 \%)$ followed by the business professionals $(35 \%)$. The percentage of the professions is thus seen to vary in different studies, largely due to the differences in the occupational patterns and the source from where the patients were selected.

Sexual route (heterosexual) was found to be the major risk factor $(86 \%)$. Other Indian studies also showed unprotected heterosexual sex as the commonest mode of transmission $[15,16]$.

In this study, fever was the most common complaint $(93 \%)$ followed by loss of appetite $(80 \%)$ and cough $(64 \%)$. These findings are in agreement with the other findings $[13,17,18]$. They indicate that both HIV infected \& non HIV infected persons have similar presenting complaints. Thus, physicians should aggressively pursue a diagnosis of TB in HIV infected persons presenting with these complaints and vice versa.

Tuberculosis, unlike other HIV-associated opportunistic infections, may occur at relatively high levels of CD4 counts, although its frequency markedly increases in patients with more severe immunosuppression. The patients of concurrent HIV-TB, when first reported, had a mean CD4 of 110.4 cells $/ \mu \mathrm{l}$ (range $28-321)$. As many as $52(40.2 \%)$ out of 87 patients had initial CD4 counts less than 200, signifying advanced disease. HIV-TB cases have been observed to have severe immunosuppression at presentation, with several studies reporting CD4 counts of less than $200[19,20]$. Comparative studies from India have also reported significantly lower CD4 counts in patients with HIV-tuberculosis than HIV alone [21, 22]. Pulmonary tuberculosis only was found in $32.2 \%$ patients and EPTB in $48.2 \%$ patients. Seventeen patients (19.5\%) had both pulmonary and extrapulmonary tuberculosis. Other studies also reported higher prevalence of EPTB of $53-63 \%$ of total tuberculosiscases in HIV-infected patients, and was seen more frequently in severely immunocompromised HIV patients [23, 24].

Commonest form of EPTB in our study group was lymph node tuberculosis diagnosed in 19 patients followed by CNS tuberculosis in 13, abdominal tuberculosis in 11 , genital tuberculosis in 8 , pleural effusion in 7 and tubercular pericardial effusion in one patient. S K Sharma et al. [3] in a study on EPTB in HIV-positive patients also noted lymph node involvement as the most common EPTB site followed by spleen [25].

Tuberculin positivity was stratified by both $5 \mathrm{~mm}$ and $10 \mathrm{~mm}$ cut-offs and by CD4 count strata was maximum when considering induration of $5 \mathrm{~mm}$ in patients with CD4 cell count, both above and below 200 cells $/ \mu \mathrm{l}$. Other workers also recorded low tuberculin reactivity $(30-50 \%)$ which is due to depression of cell mediated immunity in HIV infected persons [25]. So tuberculin test is not of much value in HIV infected persons particularly those with advanced disease. There are limited benefits in using a $5 \mathrm{~mm}$ induration cut-off to define a positive TST in HIV-positive patients as compared to the $10 \mathrm{~mm}$ cut-off used in non-HIV-infected patients [26]. However, in our study at CD4 counts $<100$ cells/mm [31], the $5 \mathrm{~mm}$ cut-off detected nearly twice as many cases of TB as the $10 \mathrm{~mm}$ cut-off. The more sensitive 5 mmcut-off may therefore still be beneficial in this 
subset of severely immunosuppressed patients. Many clinicians in India and other countries still rely on TST as part of their diagnostic workup for active TB. These data show that TST should not be used as sole diagnostic marker, especially in HIV-infected individuals.

CXR changes in TB/HIV patients reflect the degree of immunocompromised status. In mild immunocompromised patients, the appearance is often classical (with cavitation and upper lobe infiltrates) whereas in severe immunocompromised status, the appearance is often atypical $[9,26]$.

HIV infection compromises the validity and effectiveness of chest radiography in the diagnosis of pulmonary $\mathrm{TB}$ in HIV-infected persons, and the findings could be normal for up to $14 \%$ of HIV-infected persons who have culture-confirmed pulmonary TB [27]. A normal CXR at the time of presentation with $\mathrm{PTB}$ represents a major obstacle to PTB diagnosis. Our findings of $3(6.7 \%)$ normal CXRs in PTB patients are consistent with previously published estimates of HIV-infected patients presenting withnormal CXRs of approximately 2-22\% [27-30]. Along with limited sensitivity of CXR in patients with HIV infection is the problem of specificity, as the differential diagnosis for an abnormal CXR in an HIV-infected patient is broad and may include common opportunistic infections such as bacterial and fungal pneumonia. However, an abnormal CXR still remains a useful tool in PTB suspects, and the positive predictive value of CXR for PTB will likely remain high in settings with high TB prevalence. We found that for HIV-seropositive patients with $\mathrm{CD} 4$ counts of $<200$ cells $/ \mu 1$, the sensitivity of a typical post-primary pattern CXR for identifying active pulmonary TB is poor. $57 \%$ patients with a CD4 $<200$ had atypical findings (intrathoracic adenopathy, focal lower or middle lobe infiltrates and diffuse military or nodular infiltrates) while only $28 \%$ had typical radiographic findings. Similar conclusions have been found in other studies. Greenburg et al [28] retrospectively reviewed the chest radiographs of 48 HIV-seropositive patients with pulmonary $\mathrm{TB}$ and CD4 counts of $<200$ cells $/ \mu$ land found that only $23 \%$ of patients had radiographic findings typical of post-primary TB. They also evaluated the CXR findings of $20 \mathrm{HIV}$-seropositive patients with CD4 counts of $>200$ cells $/ \mu \mathrm{L}$. In this subpopulation, 11 of 20 (55\%) of patients' CXRs showed post-primary TB. However, chest radiography remains an important adjunct in the diagnosis of TB, and its use must be expanded, including the use of advanced and innovative technology, such as digital imaging [3].

Diagnosis of active tuberculosis in HIV-infected persons is difficult, because patients with HIV-associated TB have fewer bacilli in their sputum [31] than do HIV-uninfected patients with pulmonary TB. The sputum positivity in pulmonary involvement of $37 \%$ seen in this study was similar to that reported from India [32]. It has been reported that as immune suppression increases the smear negativity also increases.

Because diagnosis in most regions depends on microscopic examination of Ziehl-Neelsen-stained sputum smears, which has low sensitivity among HIV-infected persons, most HIV infected persons are not tested with the standard diagnostic methodology. Mycobacterial culture is the gold standard for tuberculosis diagnosis and should be routinely done to assist the diagnosis of tuberculosis in HIV-infected persons. Automated liquid culture systems are being evaluated for use in resource poor settings [33] for better and earlier results.

\section{References}

[1] UNAIDS World AIDS Day Report, 2011.

[2] Annual Report 2010-11, Department of AIDS Control National AIDS Control Organisation Ministry of Health \& Family Welfare Government of India.

[3] S. K. Sharma, A. Mohan and T. Kadhiravan, HIV-TB co-infection: Epidemiology, diagnosis and management, Indian J Med Res 121 (2005) 550-567. 
[4] S. Solomon, S. Anurodha and S. Rajasekharan, Trend ofHIV infection in patients with pulmonary tuberculosis in South India, Tuberc and Lung Dis 76 (1995) 17.

[5] TB/HIV: A Clinical Manual (2nd Ed.), World Health Organization, 2004.

[6] Annual Report 2010-11, Department of AIDS Control National AIDS Control Organisation Ministry of Health \& Family Welfare Government of India, Central TB Division. TB India 2007; RNTCP status report. New Delhi: Central TB Division, Directorate General of Health Services, Ministry of Health and Family Welfare, Govt. of India. 2007, p. 10.

[7] E. L. Corbett, C. J. Watt, N. Walker, D. Maher, B. G. Williams, M. C. Raviglione and C. Dye, The growing burden of tuberculosis: global trends and interactions with the HIV epidemic, Archives of Internal Medicine 163 (2003) 1009-1021.

[8] S. Swaminathan and G. Narendran, $2008 \mathrm{HIV}$ and tuberculosis in India, J. Biosci. 33 (2008) 527-537.

[9] B. Jones, S. Young, D. Antoniskis, P. Davidson, F. Kramer and P. Barnes, Relationship of themanifestations of tuberculosis to CD4 cell counts in patients with human immunodeficiency virusinfection, Am Rev Respir Dis 148 (1993) 1292-1297.

[10] Guidelines for HIV testing, March 2007, Department of AIDS Control National AIDS Control Organisation Ministry of Health \& Family Welfare Government of India.

[11] C. N. Deivanayagam, S. Rajasekaran, V. Senthilnathan, R. Krishnarajsekhar, K. Raja and C. Chandrasekar et al., Clinico-radiological spectrum of tuberculosis among HIV seropositives: A Tambram study, Indian J. Tuberc 48 (2001) 123 .

[12] D. S. Bhagyabati, S. Naorem, T. J. Singh, K. B. Singh and L. Prasad and T. Shantidevi, HIV and TB Co-infection, Indian Academy of Clinical Medicine 6 (2005) 220.

[13] K. C. Mohanty, R. M. Sundrani and S. Nair, HIV infection in patients with respiratory disease, Indian $\mathrm{J}$ Tuberc 40 (1993) 5.

[14] R. Rajasekaran, A. Lima, S. Kamakshi, D. Jeyaganesh, A. Senthamizhchelvan and S. Savithrr et al., Trend of HIV infection in patients with tuberculosisin rural south India, Indian J Tuberc 47 (2000) 223.

[15] A. K. Adhikari, Clinical spectrum of patients of HIV/AIDS, J Assoc Physicians India 51 (2003) 1258.

[16] N. Kumarasamy, S. Solomon, S. A. Jayaker Paul, R. Venilla and R. E. Amalraj, Spectrum of opportunistic infections among AIDS patients in Tamilnadu, India. Int J AIDS 6 (1995) 447-449.
[17] S. D. Purohit, R. C. Gupta and V. K. Bhatura, Pulmonary tuberculosis and human immunodeficiency virus infection in Ajmer, Lung India 14 (1996) 113-120.

[18] S. Mohd and A. Zuber, Manifestations of tuberculosis in HIV infected patients, J Indian AcadClin Med 6 (2005) 302-305.

[19] E. Girardi, G. Antonucci and P. Vanacore et al., Tuberculosis in HIV-infected persons in the context of wide availability of highly active antiretroviral therapy, EurRespir J 24 (2004) 11-17.

[20] B. E. Jones, S. M. M. Young and D. Antoniskis et al., Relationship of the manifestations of tuberculosis to CD4 cell counts in patients with human immunodeficiency virus infection, Am Rev Respir Dis 148 (1993) 1292-1297

[21] M. Vajpayee, S. Kanswal, P. Seth, N. Wig and R. M. Pandey, Tuberculosis infection in HIV-infected Indian patients, AIDS Patient Care STDs 18 (2004) 209-213.

[22] A. Jaryal, R. Raina, M. Sarkar and A. Sharma, Manifestations of tuberculosis in HIV/AIDS patients and its relationship with CD4 count, Lung India 28 (2011) 263-266.

[23] C. Perronne, M. Zahraoui, C. Leport, D. Salmon, B. Pangon and F. Bricaire et al., Tuberculosis in patients infected with the human immunodeficiencyvirus, Presse Med 17 (1988) 1479-1483.

[24] B. E. Jones, S. M. Young, D. Antoniskis, P. T. Davidson, F. Kramer and P. F. Barner, Relationship of the manifestations of tuberculosis to CD4 cell counts in patients with human immunodeficiency virus infection, Am Rev RespirDis 148 (1993) 1292-1297.

[25] S. K. Sharma, R. B. Deoskar, K. E. Rajan and M. S. Barthwal, Extra pulmonary tuberculosis in HIV infection, Med J Armed Forces India 61 (2005) 340-341.

[26] F. A. Post, R. Wood and G. P. Pillay, Pulmonary tuberculosis in HIV infection: radiographic appearance isrelated to CD4+ T-lymphocyte count, Tubercle Lung Dis 76 (1995) 518-521.

[27] R. Long, B. Maycher and M. Scalcini et al., The chest roentgenogram in pulmonary tuberculosis patients seropositive for human immunodeficiency virus type 1 , Chest 99 (1991) 123-127.

[28] S. Greenberg, D. Frader and B. Suster et al., Active pulmonary tuberculosis in patients with AIDS: Spectrum of radiographic findings, Radiology 193 (1994) 115-119.

[29] J. M. FitzGerald, S. Grzybowski and E. A. Allen, The impact of human immunodeficiency virus infection on tuberculosis and its control, Chest 1 (1991) 191-200.

[30] M. Keiper, M. Beumont and A. Elshami et al., CD4 T lymphocyte count and the radiographic presentation of pulmonary tuberculosis, Chest 107 (1995) 74-80. 
[31] R. J. Brindle, P. P. Nunn and B. I. Batchelor et al., Infection and morbidity in patients with tuberculosis in Nairobi, Kenya, AIDS 7 (1993) 1469-1474.

[32] D. C. Perman, W. M. El-Sadr and E. T. Nelson et al., Variation of chest radiographic patterns in pulmonary tuberculosis by degreeof human immunodeficiency virus-related immunosuppression, Clin Infect Dis 25 (1997) 242-246.
[33] A. Gil-Setas, L. Torroba, J. L. Fernandez, V. Martinez-Artola and J. Olite, Evaluation of the MB/BacT system compared withMiddlebrook 7H11 and Lowenstein-Jensen media for detectionand recovery of mycobacteria from clinical specimens, Clin.Microbiol. Infect. 10 (2004) 224-228. 